\title{
RESEARCH ON THE GRINDING PERFORMANCE OF HIGH PRESSURE SINTERING SiCp/AI MATRIX COMPOSITES
}

\author{
Zhiru Chen, Changyun Li, Lei Xu*, Guofa Mi, Yukun Hu
}

School of Science and Engineering Materials, Henan Polytechnic University, Henan, Jiaozuo, 454003, P. R. China

\begin{tabular}{l} 
ARTICLE INFO \\
\hline Article history: \\
Received: 1.03 .2016$. \\
Received in revised form: 12.05 .2016$. \\
Accepted: 13.05 .2016$. \\
\hline Keywords: \\
SiC p/Al composite \\
Grinding Performance \\
Grinding Morphology \\
\end{tabular}

\section{Introduction}

With the development of science and technology, especially in the fields of aerospace, transportation, ocean engineering and precision instruments, the requirement for high performance materials is becoming more and more urgent. On the one hand, materials are required to achieve high specific strength, high stiffness, fatigue resistance, etc. On the other hand, the materials need to adapt to the working environment of high temperature and pressure, fine vacuum, and deep etching [1-4]. Most of the traditional materials cannot meet the requirements mentioned above, promoting the development of composite materials [5]. The aluminum matrix composites strengthened by $\mathrm{SiC}$ particles have some good performances, such as low density, high specific strength, and specific stiffness, high thermal conductivity, small linear expansibility, low dilatation, good dimensional stability and wear resistance, corrosion resistance, ray resistance etc. [6-9]. Besides, the raw materials

\begin{abstract}
:
The two-dimensional vertical grinding test equipment was used to grind $\mathrm{SiC}_{p} / \mathrm{Al}$ composites which were prepared by high pressure sintering method. The SEM observation of grinding morphology showed that grinding damage can be prevented by $\mathrm{SiC}$ particles reinforcement, 60\% volume fraction of $\mathrm{SiC}$ particles of $\mathrm{SiC}_{p} / \mathrm{Al}$ composite can hinder grinding depth and grinding performance was improved with the sintering pressure and temperature increasing. In addition, some scratches and exfoliated pits of SiC particles were observed on the surface of $60 \%$ volume $\mathrm{SiC}_{p} / \mathrm{Al}$ composite as the increase of grinding grain, while the depth of these scratches was shallower, there was no large area exfoliated pits of $\mathrm{SiC}$ reinforcements.
\end{abstract}

of $\mathrm{SiC}$ reinforced aluminum matrix composites can be obtained easily, so the manufacturing cost is low and the material can be adapted to market easily. It is a new structure material possessing great development potential [10].

Although aluminum matrix composites strengthened by $\mathrm{SiC}$ particles have eminent application value in the field of aerospace, electronic packaging, and some other fields, the problem is that this kind of material could not be fabricated easily. It has a wide range of practical significance for us to do research on $\mathrm{SiCp} / \mathrm{Al}$ matrix composites in grinding performance, because grinding has some advantages like high machining accuracy, less material consumption, integrated machined surface, and low grinding surface roughness [11-13].

In the aluminum matrix composite, the $\mathrm{SiC}$ particles have characteristics of high elastic modulus and wear resistance [14]. The aluminum matrix composites which are prepared under low pressure have some shortcomings, like low relative density, many internal cavities, and unevenly distributed 
silicon carbide $[15,16]$, where all of these would affect the quality of grinding surface. In order to solve these problems, high pressure sintering method is applied in this study to prepare $\mathrm{SiC}_{\mathrm{p}} / \mathrm{Al}$ composites [17]. The grinding performance of $\mathrm{SiC}_{\mathrm{p}} / \mathrm{Al}$ matrix composites will be studied by analyzing the grinding morphology and grinding mechanism under the preparation condition of different pressures, temperatures and volume fractions [18].

\section{Experimental methods}

These SiC particles whose content of $\mathrm{SiC}$ is about $96 \%$ were used as reinforcement materials which were produced by Zhengzhou Deli Company. The particle size, density, and melting point of the irregular, light green $\mathrm{SiC}$ particles are $20 \mu \mathrm{m}, 3.2$ $\mathrm{g} / \mathrm{cm}^{3}$ and $2700{ }^{\circ} \mathrm{C}$ respectively. The atomized ZL101A powders and passivation nano-aluminum powders were chosen as aluminum matrix. Passivated nano-aluminum powders were produced by Jiaozuo Banlv Na-no Material Engineering Company Limited, the particle size of ZL101A powder is between $150 \mu \mathrm{m}$ and $212 \mu \mathrm{m}$, while the size of the black nano-aluminum powder is $80 \mathrm{~nm}$.

Table.1 The preparation conditions of $\mathrm{SiC}_{\mathrm{p}} / \mathrm{Al}$ samples

\begin{tabular}{|c|c|c|c|}
\hline & $\begin{array}{c}\text { Volume fraction } \\
(\text { Vol-\% })\end{array}$ & $\begin{array}{c}\text { Pressure } \\
(\mathrm{GPa})\end{array}$ & $\begin{array}{c}\text { Temperature } \\
\left({ }^{\circ} \mathrm{C}\right)\end{array}$ \\
\hline $1 \#$ & 20 & 4.6 & 500 \\
\hline $2 \#$ & 40 & 3.0 & 500 \\
\hline $3 \#$ & 40 & 3.8 & 500 \\
\hline $4 \#$ & 40 & 4.6 & 500 \\
\hline $5 \#$ & 60 & 4.6 & 500 \\
\hline $6 \#$ & 60 & 4.6 & 620 \\
\hline $7 \#$ & 60 & 4.6 & 740 \\
\hline
\end{tabular}

The "Nano-aluminum-SiC" blending powder had been used in making $\mathrm{SiC}_{\mathrm{p}} / \mathrm{Al}$ composites. The $\mathrm{SiC}$ particles were surrounded by a layer of nanoaluminum powers, which can reduce the agglomeration of the $\mathrm{SiC}$ particles. The $\mathrm{SiC}_{\mathrm{p}} / \mathrm{Al}$ composites were prepared with conditions of different volume fractions, pressures, and temperatures by the method of high-pressure sintering with six-face presser machine, as shown in the Table 1. For this purpose, the density and hardness of $\mathrm{SiC}_{\mathrm{p}} / \mathrm{Al}$ composites will be improved, which can show superior grinding performance. The grinding experiment of $\mathrm{SiC}_{\mathrm{p}} / \mathrm{Al}$ matrix composites were tested by the two-dimensional vertical grinding test equipments. An iron plate of $140 \mathrm{~mm} \times 30 \mathrm{~mm} \times 15 \mathrm{~mm}$ in size was adopted to splice all samples. Two grain sizes of $500 \#$ and $110 \#$ of grinding wheel were chosen to do the grinding experiment at the rotating velocity of $600 \mathrm{~m} / \mathrm{min}$, reciprocating speed of $20 \mathrm{~m} / \mathrm{min}$ on the surface of samples under dry condition. After the grinding tests had been undergone for $10 \mathrm{~min}$, all samples were cleaned up and dried. The grinding property of $\mathrm{SiC}_{\mathrm{p}} / \mathrm{Al}$ matrix composites were analyzed through the SEM micrographs of grinding surface morphology.

\section{The results and discussion}

\subsection{The effect of different volume fractions of $\mathrm{SiC}$ on the grinding performance}

Fig. 1 shows the microscopic images of $\mathrm{SiC}_{\mathrm{p}} / \mathrm{Al}$ matrix composite material with volume fraction of $\mathrm{SiC}$ of $20 \%, 40 \%$ and $60 \%$ respectively, which were obtained at the same temperature and pressure condition of $500{ }^{\circ} \mathrm{C}$ and $4.6 \mathrm{GPa}$.

The grinding of $\mathrm{SiC}_{\mathrm{p}} / \mathrm{Al}$ matrix composites sample under the volume fraction of $20 \%$ was smoother as shown in the Fig 1. in Here shallow furrow stripes appeared and grinding marks of $40 \%$ volume fraction $\mathrm{SiC}_{\mathrm{p}} / \mathrm{Al}$ matrix composites bend. Al alloy matrix was ductile cut and extrusion was coated on a workpiece surface due to the increase of the $\mathrm{SiC}$ particles hindering grinding, while the $60 \%$ volume fraction $\mathrm{SiC}_{\mathrm{p}} / \mathrm{Al}$ matrix composites material showed good grinding property. Grinding scratches just existed in the aluminum matrix, and the grinding marks were not observed in other distribution of the $\mathrm{SiC}$ particles.

Furthermore, it can be seen from the Fig 2(a) that some $\mathrm{SiC}$ particles were pulled out after grinding and forming some $\mathrm{SiC}$ particles grooves [19], as shown in position 1 of the Fig 2(a). There also appeared flaking pits in the position 2 of the Fig 2(a) which shows that the composites appeared peel adhesion in the grinding process [20,21]. The same phenomenon also appeared in the $40 \%$ volume fraction $\mathrm{SiC}_{\mathrm{p}} / \mathrm{Al}$ matrix composites material, as shown in the position 3 of Fig 2(b). However, the number of these grooves had reduced significantly 
comparing them to the former grinding surface. For the $60 \%$ volume fraction $\mathrm{SiC}_{\mathrm{p}} / \mathrm{Al}$ matrix composites material, the volume fraction of $\mathrm{SiC}$ particles was bigger than of the alloy matrix, so these $\mathrm{SiC}$ particles cannot be better encapsulated. Weak bonding strength and defects exited the two-phase interface, resulting in the $\mathrm{SiC}$ particles brittle fracture or exfoliation under the influence of impact, shear, and extrusion of the grinding wheel grain. Some large area exfoliated pits of the $\mathrm{SiC}$ particles and voids had been observed as shown in the Fig $8(\mathrm{c})$, and the grinding surface became rough.
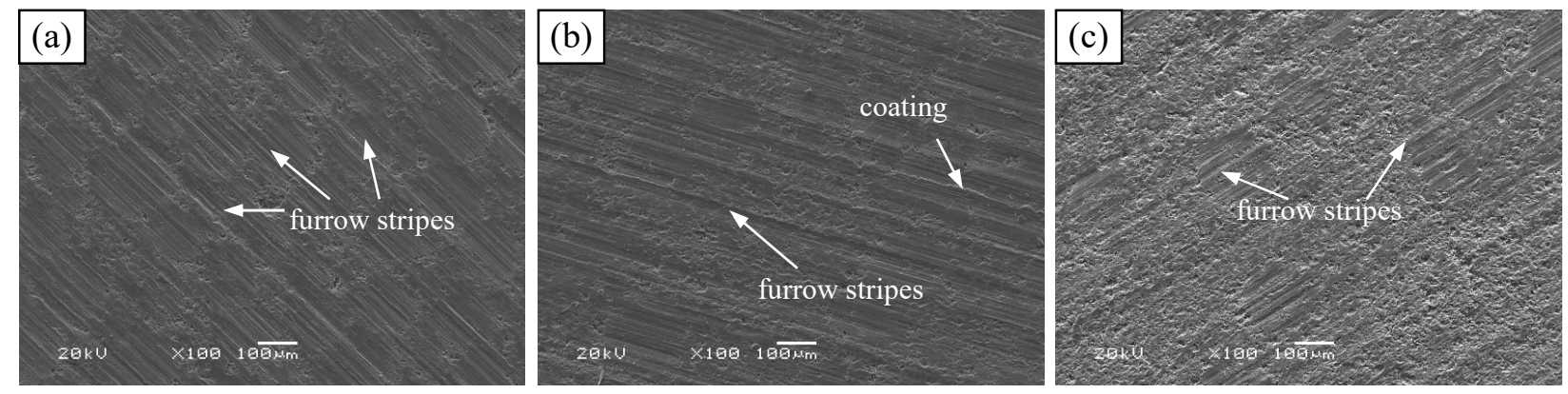

Figure 1. Grinding scanned photos under the condition of: (a)20\%-4.6 GPa-500 ${ }^{\circ} \mathrm{C}$, (b) $40 \%-4.6 \mathrm{GPa}-500$ ${ }^{\circ} \mathrm{C}$ and (c) $60 \%-4.6 \mathrm{GPa}-500{ }^{\circ} \mathrm{C}$
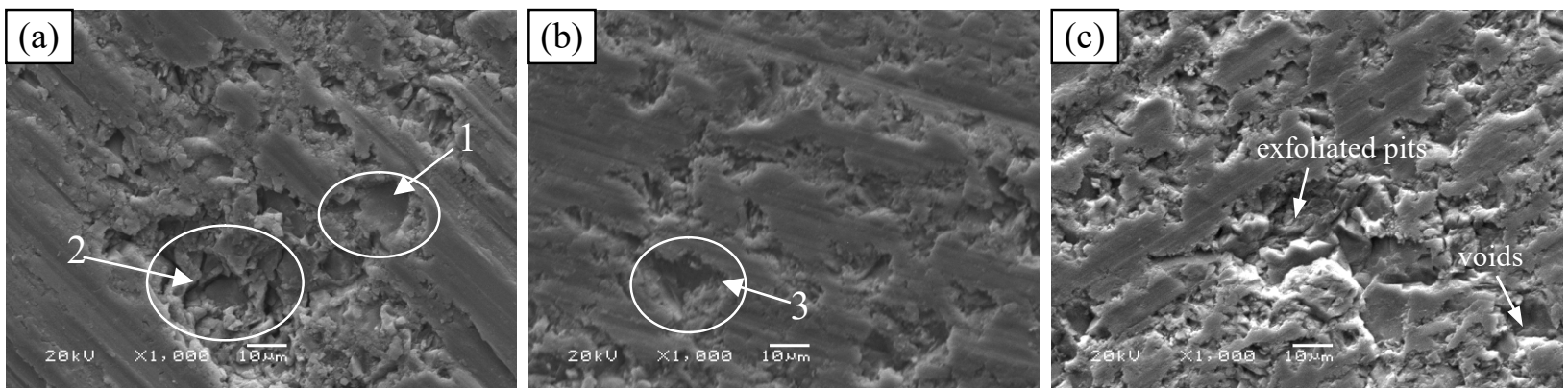

Figure 2. Grinding scanned photos under the condition of: (a)20\%-4.6 GPa-500 ${ }^{\circ} \mathrm{C}$, (b) $40 \%-4.6 \mathrm{GPa}-500$ ${ }^{\circ} \mathrm{C}$ and (c) $60 \%-4.6 \mathrm{GPa}-500{ }^{\circ} \mathrm{C}$
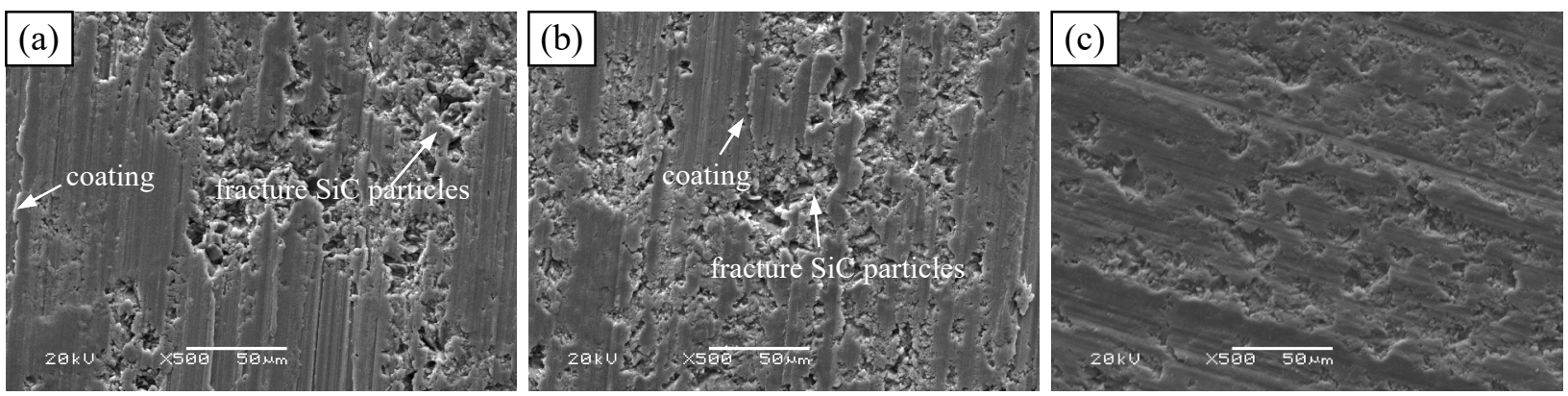

Figure 3. Grinding scanned photos under the condition of:(a) $3.0 \mathrm{GPa}-40 \%-500{ }^{\circ} \mathrm{C}$, (b) $3.8 \mathrm{GPa}-40 \%-500{ }^{\circ} \mathrm{C}$ and (c) $4.6 \mathrm{GPa}-40 \%-500{ }^{\circ} \mathrm{C}$

\subsection{The Effect of preparation pressure on the grinding performance of composites}

Fig. 3 shows the microscopic images of $\mathrm{SiC}_{\mathrm{p}} / \mathrm{Al}$ matrix composite material with pressure condition of $\mathrm{SiC}$ of $3.0 \mathrm{GPa}, 3.8 \mathrm{GPa}$ and $4.6 \mathrm{GPa}$ respectively, which were obtained at the same volume fraction and temperature of $60 \%$ and $500^{\circ} \mathrm{C}$.

It can be seen from the Fig 3. that the surface morphology after grinding under the pressure of 4.6GPa was superior to other pressures, and the 
grinding morphology under $3.0 \mathrm{GPa}$ and $3.8 \mathrm{GPa}$ was slightly inferior. Many $\mathrm{SiC}$ particles peeled from the substrate easily and some fractured. The $\mathrm{SiC}$ particles had been pressed into the surface, as it is presented in the Fig. 3(a) and Fig. 3(b). This happened due to the weak bonding strength between Al alloy matrix and the SiC particles being under low preparation pressure This shows that the grinding performance will be improved with an increase of preparation pressure.

\subsection{The effect of preparation temperature on the grinding performance of composites}

Fig. 4 shows the microscopic images of $\mathrm{SiC}_{\mathrm{p}} / \mathrm{Al}$ matrix composite material with temperature of $\mathrm{SiC}$ of $500{ }^{\circ} \mathrm{C}, 620{ }^{\circ} \mathrm{C}$ and $740{ }^{\circ} \mathrm{C}$ respectively, which were obtained at the same volume fraction and pressure condition of $60 \%$ and $4.6 \mathrm{GPa}$.

The metal matrix composites reinforced by the high volume fraction from the $\mathrm{SiC}$ particles can be prepared by the high-pressure method easily comparing a powder metallurgy and stirring casting [22].

Fig. 4 showed that some SiC particles had peeled off the aluminum matrix under the grinding force, while some grooves of different sizes were formed. The less volume fraction of aluminum matrix results. The combined area and binding force between silicon carbide particles and aluminum matrix are small in the reinforced aluminum matrix composite of high volume fraction of the $\mathrm{SiC}$ particles. Therefore, the reinforced particles cannot be fixed well. At last, the $\mathrm{SiC}$ particles will be grounded easily during the grinding process. TheAl alloy matrix would become soft and would get higher deformation resistance with the increasing of temperature. In this way the voids between particles can be filled with the softening $\mathrm{Al}$ matrix, and the compactness of composite can be promoted. The composite would have a better property to resist the grinding of the grinding wheel grain. large amount of exfoliated pits can be seen in the Fig 5(a), which led to the appearance of an uneven surface of the composites. The number of exfoliated pits reduced slightly under the sintering temperature of $620{ }^{\circ} \mathrm{C}$, as shown in the Fig. 5(b). When the sintering temperature reached $740{ }^{\circ} \mathrm{C}$, scratches on samples were shallower and exfoliated pits distributed, which can be observed in the Fig. 5(c).

When the composites were achieved under the maximum volume fraction, the pressure and temperature of $60 \%, 4.6 \mathrm{GPa}$ and $740{ }^{\circ} \mathrm{C}$, the content of silicon was higher than aluminum as shown in the Fig 5. This is consistent with the volume fraction of the $\mathrm{SiC}$ particles being that the weight percentage of Si element is six times greater of Al element in the Fig. 5(b).

Fig. 6 is the SEM micrographs of grinding surface morphology of the sample $1 \#$ under different wheel grain sizes of $110 \#$ and 500\#.

Fig. 6(a) indicates that some slight grinding marks had appeared, a few spherical grindings can be seen on the surface of organization. As shown in the Fig. 6(b), it can be observed that the scratches and abscission pits of the $\mathrm{SiC}$ reinforced particles had appeared on the surface of the $\mathrm{SiC}_{\mathrm{p}} / \mathrm{Al}$ matrix composites material with the increase of grain size, while these grinding scratches were shallow, and no large area of the enhanced matrix abscission pits appeared.
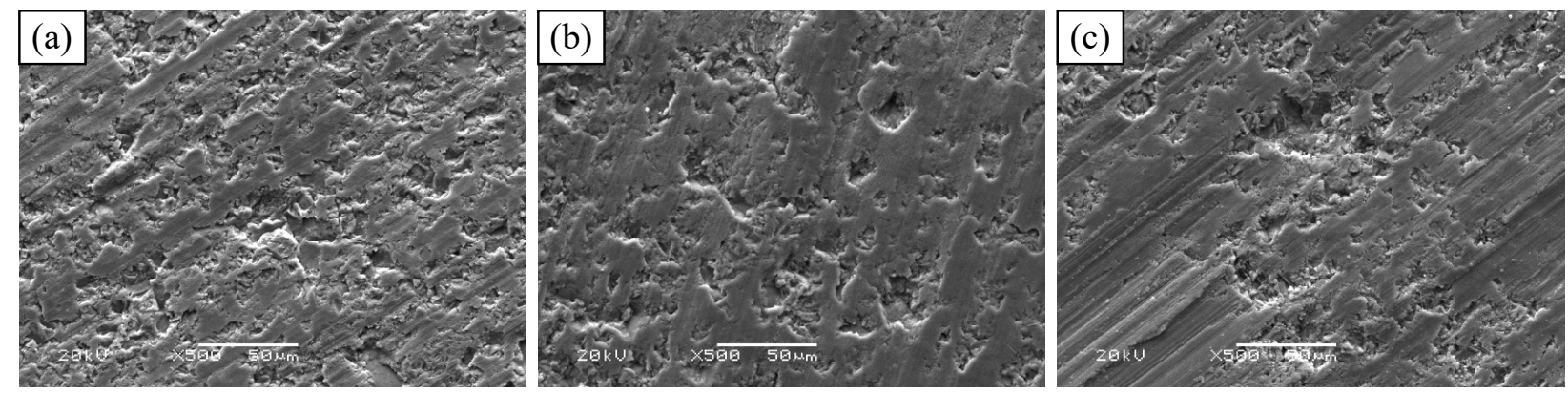

Figure 4. Grinding scanned photos under the condition of: (a) $500{ }^{\circ} \mathrm{C}-60 \%-4.6 \mathrm{GPa}$, (b) $620{ }^{\circ} \mathrm{C}-60 \%-4.6$ $\mathrm{GPa}$ and (c) $740{ }^{\circ} \mathrm{C}-60 \%-4.6 \mathrm{GPa}$ 

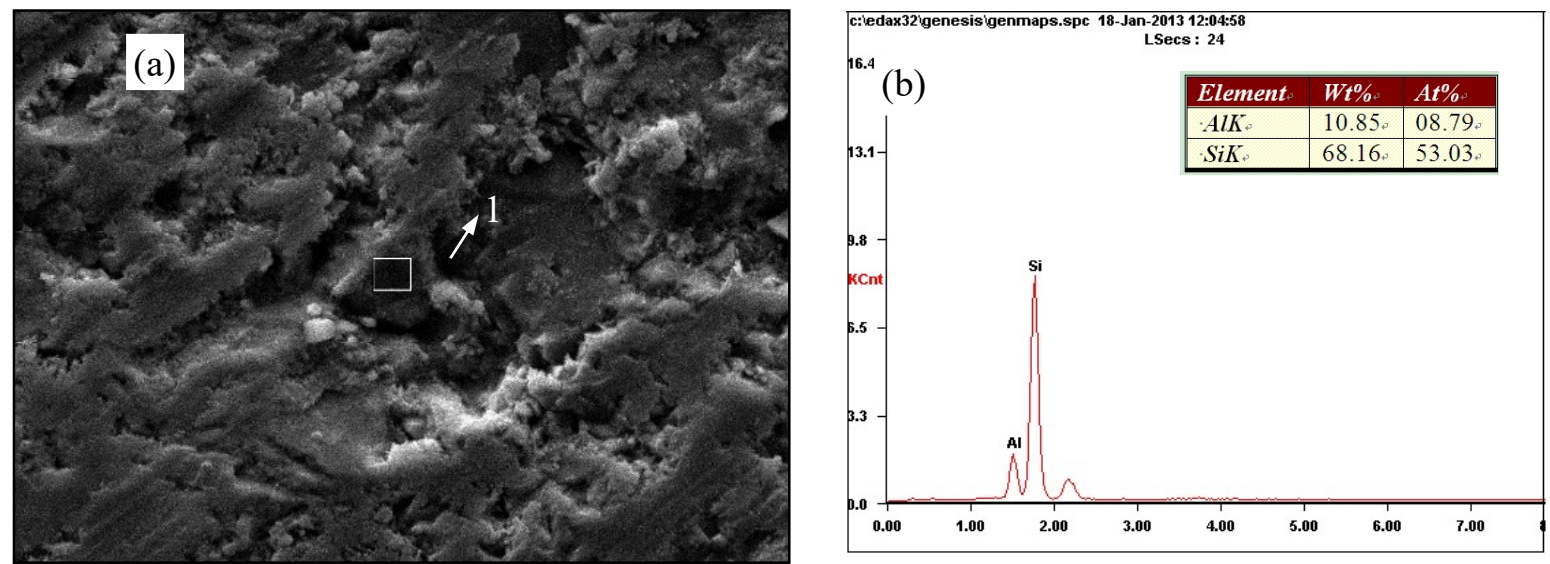

Figure 5. Regional scanning graphs (a) SEM micrographs (b) EDS analysis of region-1
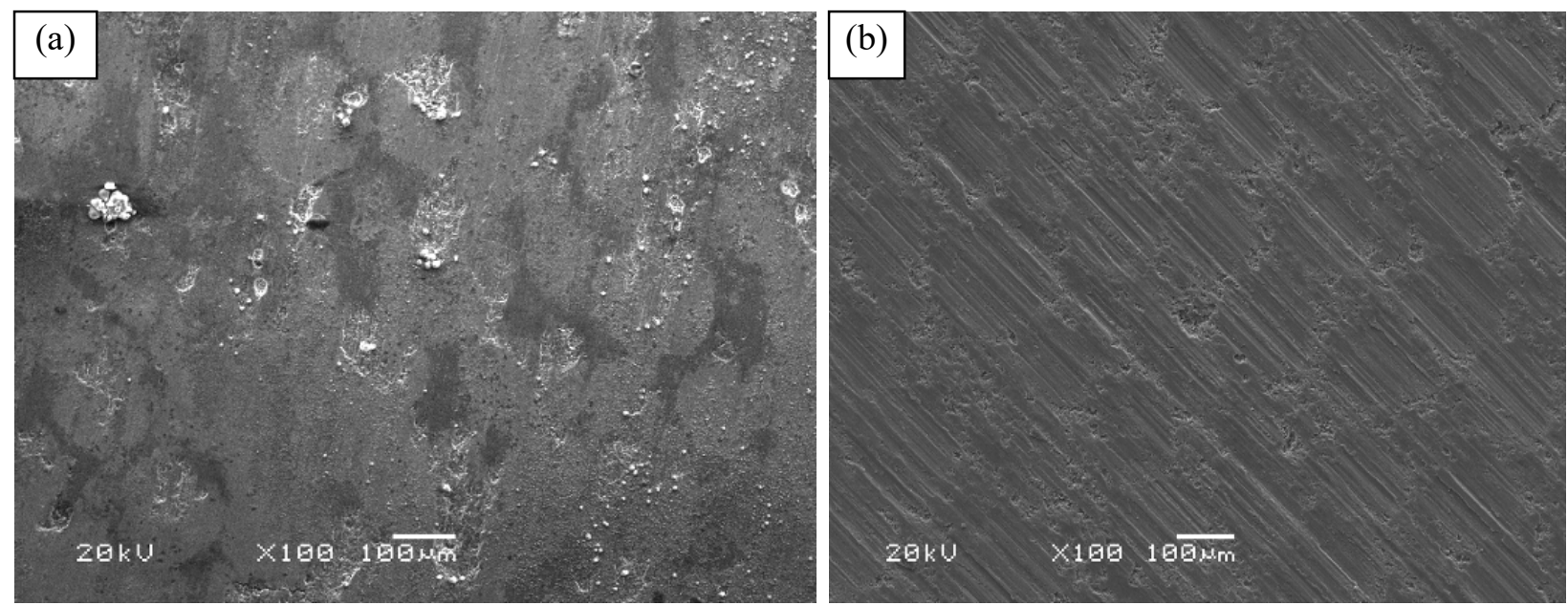

Figure 6. SEM micrographs of grinding surface morphology of the samples under different grain size conditions of: (a) grinding surface morphology of 500\# grain and (b) grinding surface morphology of 110\# grain
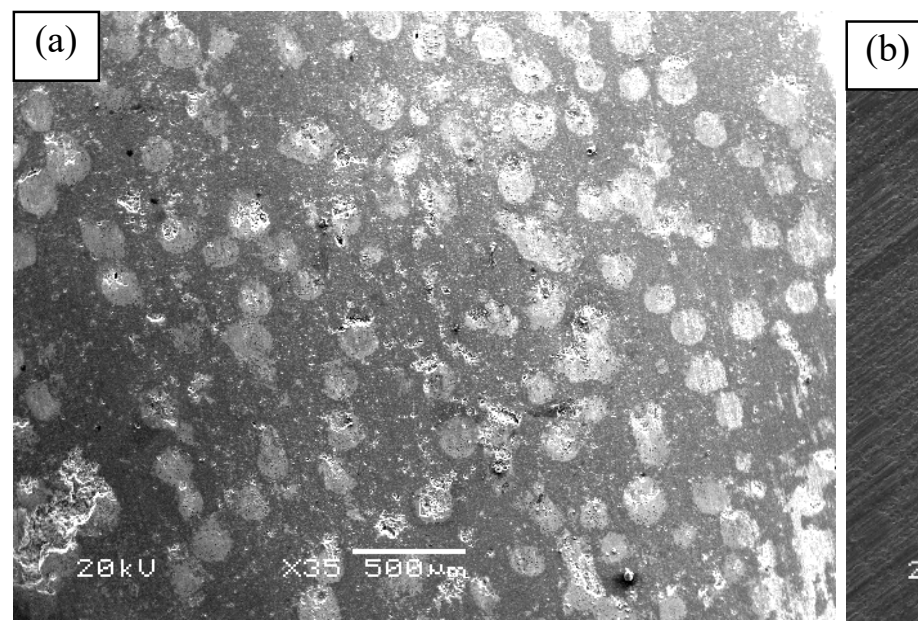

Figure 7. SEM micrographs of grinding surface morphology of the high volume fraction samples under different grain size conditions of: (a) grinding surface morphology of 500\# grain and (b) grinding surface morphology of 110\# grain 
Fig. 7 is the SEM micrographs of grinding surface morphology of sample $6 \#$ that $\mathrm{SiC}_{\mathrm{p}} / \mathrm{Al}$ matrix composite with $\mathrm{SiC}$ volume fraction of $60 \%$ under different wheel grain sizes of $110 \#$ and 500\#.

It is obvious from the Fig. 7(a) that only some small abscission pits of reinforced particles had appeared on the surface of the $\mathrm{SiC}_{\mathrm{p}} / \mathrm{Al}$ matrix composites with the $\mathrm{SiC}$ volume fraction of $60 \%$ after being ground by the $500 \#$ grinding wheel. Due to the content of the $\mathrm{SiC}$ reinforced particles beinghigh, and aluminum matrix content relatively low, this led to the combined strength of reinforcement not being stronger than the low volume fraction composites. The reinforced $\mathrm{SiC}$ particles of high volume fraction $\mathrm{SiC}_{\mathrm{p}} / \mathrm{Al}$ matrix composites can reduce grinding damage under the condition of the grinding wheel grain 110\#, as shown in the Fig. 7(b). The grinding morphology was better than the low volume fraction composite, just some shallow scratches appeared during the grinding process. The grinding surface of the grinding wheel grain $110 \#$ was much rougher than $500 \#$.

Different grinding characteristics of high pressure sintering of $\mathrm{SiC}_{\mathrm{p}} / \mathrm{Al}$ matrix composites can be found in the Fig. 6 and the Fig. 7 under the different grinding wheel grain sizes. The samples showed better grinding ability when ground by the smaller wheel grain. The reason for this phenomenon is that the grain size of $500 \#$ reaches $20 \mu \mathrm{m}$, and the $\mathrm{SiC}$ particles size is $20 \mu \mathrm{m}$, so these $\mathrm{SiC}$ particles cannot be pull out easily. When grinding process of $110 \#$ grinding wheel with the grain size of $135 \mu \mathrm{m}$ happened, these $\mathrm{SiC}$ particles would be pulled out or broken quickly, while Al matrix would present furrow stripes under the grinding force.

\section{Conclusion}

(1) When the content of $\mathrm{SiC}_{\mathrm{p}}$ is very low, some $\mathrm{SiC}$ particles are pulled out after grinding and some $\mathrm{SiC}$ particles form grooves; the grinding of $\mathrm{SiC}_{\mathrm{p}} / \mathrm{Al}$ matrix composites under the volume fraction of $20 \%$ is more smooth, and some shallow furrow stripes have appeared; due to the high content of the $\mathrm{SiC}$ particles hindering the grinding process, the grinding marks of $40 \%$ volume fraction $\mathrm{SiC}_{\mathrm{p}} / \mathrm{Al}$ matrix composites appeared bending compared with the low volume fraction $\mathrm{SiC}_{\mathrm{p}} / \mathrm{Al}$ matrix composites; while the $60 \%$ volume fraction $\mathrm{SiC}_{\mathrm{p}} / \mathrm{Al}$ matrix composites show good grinding resistance, the grinding scratches exists just in the aluminum matrix, and the other parts of the SiC particles don't leave obvious grinding marks. Adhesion spalling has occurred during the grinding process; the grinding performance at the same temperature, and pressure conditions of $500{ }^{\circ} \mathrm{C}$ and $4.6 \mathrm{GPa}$ is superior to the other grinding pressure and temperature conditions.

(2) Due to the volume fraction of the aluminum matrix in $60 \%$ volume fraction of the $\mathrm{SiC}_{\mathrm{p}} / \mathrm{Al}$ matrix composites are less, which leads to the combined area and binding force between silicon carbide particles and aluminum matrix being small, and the reinforced particles cannot be fixed well, so the $\mathrm{SiC}$ particles will be ground easily during the grinding process. The grinding performance of high volume fraction of the $\mathrm{SiC}_{\mathrm{p}} / \mathrm{Al}$ matrix composite is superior to the low volume fraction of the $\mathrm{SiC}_{\mathrm{p}} / \mathrm{Al}$ matrix composite under the same conditions of the grinding wheel grain size.

(3) With the increase of the wheel grain size, the scratches and abscission pits of reinforced $\mathrm{SiC}$ particles happen on the surface of the $\mathrm{SiC}_{\mathrm{p}} / \mathrm{Al}$ matrix composites, while these grinding scratches are shallow. No large area of the enhanced matrix abscission pits are found.

\section{Acknowledgments}

This work has been operated with the financial support of the National Natural Science Foundation of China (Grant No. 51401077) and the Postdoctoral Science Foundation of Henan Province (Grant No. 2012052). Thanks are given to the faculty of Science and Engineering Materials of Henan Polytechnic University.

\section{References}

[1] M. Kawasaki, Y. Huang, C. Xu, M. Furukawa, Z. Horita, T.G. Langdon.: A quantitative study of cavity development in the tensile testing of an aluminum metal matrix composite processed by equal-channel angular pressing, Mater. Sci. Eng. A, 410-411(2005) 402-407.

[2] Gao. Z., Niu. J., Yang. S., Wang. X., Cheng. D.: Soldering of Aluminum Matrix Composites SiCp/A356 and Kovar Alloy, Engineering Review, 33 (2013), 2, 123-128.

[3] A. Wang, Y., Liu, X.D.: Present Status and Development Trend of SiCp/Al Composites, Research Studies on Foundry Equipment, 
(2003), 3, 18-22.

[4] B. Patel, S. Das, B.K.: Compressive deformation behaviour of Al alloy (2014)-10 wt.\% SiCp composite: Effects of strain rates and temperatures Prasad, Mater. Sci. Eng. A, 530 (2011), 225-232.

[5] Zheng, J., Jia, Z.H., Ma, G.: Development and application research present situation of silicon carbide particle reinforced aluminum matrix composites, Titanium Industry Progress, 23 (2006), 6, 13-16.

[6] Marta. Pozuelo, Wei H. Kao, Jenn-Ming Yang: High-resolution TEM characterization of SiC nanowires as reinforcements in a nanocrystalline Mg-matrix, Mater. Charact, 77 (2013), 81-88.

[7] M.R. Kamali Ardakani, S. Khorsand, S. Amirkhanlou, M. Javad Nayyeri: Application of compocasting and cross accumulative roll bonding processes for manufacturing highstrength, highly uniform and ultra-fine structured Al/SiCp nanocomposite, Mater. Sci. Eng. A, 59 2(2014), 121-127.

[8] O. Beffort, S. Long, C. Cayron, J. Kuebler, P. Buffat: Alloying effects on microstructure and mechanical properties of high volume fraction SiC-particle reinforced Al-MMCs made by squeeze casting infiltration, Compos. Sci. Technol., 67 (2007), 737-745.

[9] Liu, C.S., Zhao, B., Gao, G.F., Jiao, F.: Research on the characteristics of the cutting force in the vibration cutting of a particlereinforced metal matrix composites SiCp/Al, J. Mater. Process. Technol, 129 (2002), 196-199.

[10] Gui, M.C., Wu, J.J., Wang, D.B., Chen, C.Z.: Study on Castable ZL101A/SiCp Composites, Foundry, 50 (2001), 6, 332-336.

[11] Wang, F.S., Huang, S.T., Zhou, L.: Finite element simulation of removal mechanixm during gring of SiCp/Al composites, Diamond \& Abrasives Engineering, 31 (2011), 4, 38-45.

[12] Leng, J.F., Wu, G.H.: Status of Research on Machinability of SiCp/Al Composites, Aerospace materials \& Technology, 2007, 2, 69.

[13] Zhong, Z.W., Nguyen, P.H.: Grinding of alumina/aluminum composites, J. Mater. Process. Technol., 123 (2002), 13-17.
[14] Y. Sahin, V. Kilicli: Abrasive wear behaviour of SiCp/Al alloy composite in comparison with ausferritic ductile iron, Wear, 271 (2011), 2766-2774.

[15] Li, C.Y., Hu, Y.K., Zheng, X.J., Mi, G.F., Fu, H.Z.: Study on the microstructure of SiCp/ZL101A composites of hot sinting, Rare. Metal. Mat. Eng. 41 (2012), S2, 413-416.

[16] Jin, P., Xiao, B.L., Wang, Q.Z., Ma, Z.Y., Liu, Y., Li, S.: Effect of hot pressing temperature on microstructure and mechanical properties of $\mathrm{SiC}$ particle reinforced aluminum matrix composites, Acta Metallurgica Sinica, 47 (2011), 3, 298-304.

[17] Liu, H.Z., He, H.L., Wang, L.H., Wang, A.M., Jin, C.Q.: Synthesis of SiCp/Al Nano composites under Ultra-High Pressure, Chinese Journal of high Pressure Physics, 13 (1999), 1, 1-6.

[18] S.K. Ghosh, P. Saha, S. Kishore: Influence of size and volume fraction of $\mathrm{SiC}$ particulates on properties of ex situ reinforced $\mathrm{Al}-4.5 \mathrm{Cu}-3 \mathrm{Mg}$ metal matrix composite prepared by direct metal laser sintering process, Mater. Sci. Eng. A., 527 (2010), 4694-4701.

[19] Wang, K.F., Zheng, X.J., Mi, G.F.: Ultrasonic vibration grinding of SiCp/ZL101A composites, Ordnance Material Science and Engineering, 35 (2012), 1, 39-42.

[20] Han, Y.Y., Qiao, D., Zhang, L., Feng, D.: Study of tribological performance and mechanism of phosphonate ionic liquids for steel/aluminum contact, Tribol. Int, 84 (2015), 71-80.

[21] Sang, K.Z., Jin, Z.H.: Wear Mechanism of Reaction-sintered Silicon Carbide Composites in Dry Friction Condition, Tribology, 20 (2000), 5, 352-355.

[22] Zhao, L., Huang, S.T., Zhou, L.: Experimental study on surface grinding of high volume fraction SiCp/Al composites, Diamond \&Abrasives Engineering, 31 (2011), 4, 1-4. 